\title{
Loneliness and Interpersonal Problem Solving as Predictors of Subjective Well-Being
}

\author{
Yeliz Saygin, Seher Akdeniz, and M. Engin Deniz
}

\begin{abstract}
In this study loneliness and interpersonal problem solving were examined as predictors of subjective well-being. The study group is consisting of $\mathbf{2 5 4}$ female 238 male, totally 492 university students whose average age is $\mathbf{2 0 . 2 5}$. In this study, as a data collection tool, Subjective well-being scale Interpersonal problem solving inventory and University of California Los Angeles Loneliness Scale (UCLA) which adapted to Turkish by Demir, has been used. For the analysis of the data, linear regression analysis has been applied. According to the findings gained from the research, the interpersonal problem solving and loneliness are significant predictors of subjective well-being One finding of the research is the less interpersonal problem solving skills, such as constructive problem solving and insistent-persevering problem solving levels the less their subjective well-being levels. And also the less, approaching problems in a negative way and lack of self-confidence levels the higher their subjective-well-being levels. One another finding is the less the individuals' loneliness levels the higher their subjective well-being levels and also the higher their loneliness levels the lower their subjective well-being.
\end{abstract}

Index Terms-Interpersonal problem solving, loneliness, subjective well-being.

\section{INTRODUCTION}

It has been wandered since old times what would ameliorate the life. People desire more than just to correct their weaknesses, they also want lives imbued with meaning [1]. This need has taken its place in the psychology as term 'well-being'. The studies about well-being has started to shape since the 20. Century [2]; 'the term 'subjective well-being' which is described to be well from the perspective of the individual' has been considered as a multi-dimensional structure [3]. The relation with too many factors seems inevitable in terms of the structure of subjective well-being.

The Subjective well-being, assures the people to consider their lives in a cognitive and efficient manner. This subjective description about the qualification of life is democratic in terms of having the right to say whether their life is valuable for individuals [4]. The focal point of subjective well-being; is about why and how the life is considered through positive ways [5]. The subjective well-being is consisting of two components in general manner, cognitive and emotional. Its cognitive point of view is consisting of life satisfaction judgments; and the emotional point of view consisting of positive emotions existence, absence of negative feelings [6]-[9]. Consequently, the subjective well-being is how the

Manuscript received November 8, 2013; revised January 22, 2014

Yeliz Saygin and Seher Akdeniz are with Necmettin Erbakan University, Konya, Turkey (e-mail: yelizsaygin@gmail.com, seherakdenizpdr@hotmail.com).

M. Engin Denizis is with Y Yldız Teknik University, Istanbul, Turkey (e-mail: engindeniz2003@yahoo.com). individual decides that his life is valuable [4], consisting his happiness, peace, satisfaction and life satisfaction [10]. In moderns societies another component for the individuals to be well is assumed as their interpersonal relations quality [11].

The human as a bio-psycho-socio being, can often encounter with problems in his social relations. When some has important talents and strengths solving the interpersonal problems, others are experiencing deficiencies at that matter [2]. The interpersonal problem solving, has been described as an interpersonal and cognitive process which is aiming to determine a solution on a conflict or disagreement and appropriate for all the individuals included in it [12]. The interpersonal problem solving ability, provides the social and emotional accords of people by solving the problems deriving from the differences between their necessities or ideas, beliefs, values [13].

In the researches in the case interpersonal problem solving; the approaching problems in a negative way, and unwillingness to take responsibility was found to have a high level relation with depression and anxiety [14], [15]. Researchers have found that the interpersonal problem solving has a positive correlation with well-being in terms of constructive problem-solving and insistent-preserving approach when other negative dimensions have a negative correlation with it [14].

Another factor that affects the subjective well-being is loneliness. Even though loneliness has no common description in the literature, it can be described as an individual's having way too insufficient social relations in terms of quality and quantity [16]. Weiss has asserted that the loneliness can be a reaction to the lack of social relations he needed or even though he has the relations the lack of intimidity, sincerity and emotion in those relations what he needed [17]. On the other hand according to Sullivan, loneliness is an experience that appears when the need for interpersonal relations of the individual haven't been met or sufficient, generally undesired, unpleasant [16]. Loneliness is subjective to a great extent, the judgment of the individual on himself [18]. People may experience loneliness no matter what their ages and social situations are. One can live loneliness even when he is with others. Consequently the basement of loneliness, is made by the insufficiency of the experienced social relations and the low level of the satisfaction earned from those relations [19], [20].

On the explanations about loneliness sometimes complexities can be seen between "to be alone" (aloneness, solitude) and "loneliness". Larson, in his description of the differences between the solitude and loneliness, has explained the solitude to be segregated easily from others and loneliness to choose to be alone [21]. Jones and Hebb, are mentioning the same essential points in their description of 
loneliness; a) the loneliness is related with the lack of social relations, b) they are subjective processes which are dependent on the expectations and perception of the individuals, c) they are undesired experiences, d) the individuals develop their struggles to cope with and get over loneliness. Even though the feeling of loneliness is being experienced by too many individuals of the society, each individual is living and reflecting loneliness within his own subjective reality [22]. In that point of view, loneliness is not synonymous with being alone or social isolation. Even the individuals don't experience loneliness when they are alone, they may feel themselves too much alone when between the crowds. Another common point, is that loneliness is nearly always a life which is unpleasant, negative [16].

There are some studies in the literature showing that the subjective well-being is related with loneliness. For example in a study, the olds who felt themselves alone, had focused on negative thoughts inspite of positive expectations, as a result of it, a negative relation with loneliness and subjective well-being has been determined for old people [23]. At the same time, there are some studies showing that extroversion increased the subjective well-being [24], [25].

Taking the research results and information above, the purpose in this research has been the examination loneliness and interpersonal problems solving as predictors of subjective well-being.

\section{METHOD}

\section{A. Participants}

The survey model is adapted in the current study. The participants are students at the Faculty of Education, Necmettin Erbakan University, located in the middle of Turkey. 492 students volunteered to participate in this study, 254 of whom were female (\%51.6,) 238 were male (\%48.4). The mean age was $20.25(\mathrm{SD}=1.91)$ ranging from $17-32$ years.

\section{B. Instruments}

The Interpersonal Problem Solving Inventory (IPSI): This inventory was developed by Çam and Tümkaya as a tool for measuring problem-solving approach and skills among university students between the ages of 18-30 years old [26]. The inventory consists of five subscales and a total of 50 items. The item ratings vary between 1 (strongly disagree) and 5 (strongly agree). Higher scores obtained for each scale indicates that the characteristic about interpersonal problem-solving is higher. In factor analysis study of the inventory, a total of five factors which explained a total of $38.38 \%$ of the variance related with interpersonal problem solving were obtained. These factors were approaching problems in a negative way, constructive problem-solving, lack of self-confidence, unwillingness to take responsibility, and insistent-preserving approach. The number of items in each sub-scale was $16,16,7,5$ and 6 respectively. The correlation coefficient calculated with total scores of the sub-scales varied between .22 and .74. Internal consistency (Cronbach's alpha) coefficients of the sub-scale scores of the inventory were approaching problems in a negative way $=.91$, Constructive Problem Solving =. 88, Lack of Self Confidence $=.67$, Unwillingness to take Responsibility $=.74$, and
Insistent-preserving approach $=.70$. Test re-test correlation values on 60 students in a four week interval showed $.89, .82, .69, .76$, and .70 for the subscales, respectively [26].

University of California Los Angeles Loneliness Scale (UCLA): The UCLA -developed by Russell, Peplau, and Ferguson [27] revised by Russell, Peplau, and Cutrona [28], and adapted to Turkish participants by Demir [29] was used to measure the loneliness levels of students. The UCLA is a 20-item Likert type scale to measure the general loneliness levels of participants. The reliability coefficient of the UCLA was calculated as .94 by the Retest Method and the Cronbach's Alpha Reliability Coefficient of the UCLA was found to be .96 . The parallel form validity of the UCLA was tested with the Beck Depression Inventory and the correlation coefficient was found to be .77 [29].

The Subjective Well-Being Scale (SWS): The SWS was developed by Tuzgol Dost [30]. The scale consists of 46 items. By assessing individuals' cognitive appraisals of their lives and the frequency and intensity with which they experience negative and positive feelings, the scale intends to measure their degree of subjective well-being. The SWS includes evaluative statements about major domains of life and about positive and negative emotionality. A 5-point Likert scale is used: "(5) fully agree;" "(4) mostly agree;" "(3) "agree;" "(2) somewhat agree;" and "(1) disagree." Each item has a score ranging from 1 to 5 . There are 26 positive and 20 negative statements. In scoring, regular (positive) items are assigned points 1 to 5 , whereas negative items are assigned points 5 to 1 . The lowest possible score on the scale is 46 and the highest is 230. Higher scores indicate higher degree of subjective well-being. The construct validity of SWS was examined by principle component analysis. Factor analysis revealed a KMO coefficient of .86 . The shared variance of factors on each variable ranged from .51 to .75 . The eigen value of the SWS revealed 12 factors with values greater than 1. The first factor accounted for $24.52 \%$ of the total variance. The factors of the scale, accounted for a total variance of $63.83 \%$. The factor weights of the items on the first factor ranged from .30 to .66. For concurrent validity, correlations between scores on SWS and Beck Depression Inventory (Hisli,1989) were calculated. As to be expected, there is a significant negative relationship between scores on the two scales $(r=-70)$. Internal reliability for the SWS was a Cronbach-alfa coefficient of .93. In order to determine test re-test reliability the scale was administered to 39 persons. The time interval between two administrations was two weeks. Test re-test reliability yielded a correlation coefficient of $r=.86$

\section{Procedures}

Data collection was done during the Fall semester of the academic year of 2013-2014. First, the respective departments and programs were informed of the study and their permissions were obtained. Then the date and time of administration of the surveys were determined with the respective lecturers and students. Students completed all instruments during normal class time and under the author's supervision. Linear regression analyze was employed to analyze the data obtained by inventories used in the research. Data was analyzed using the SPSS statistical package. 


\section{FINDINGS}

When Table I examined, after insertion of five sub groups of interpersonal problem solving as an independent variable in equation, it was found that every subgroups are significant predictors of subjective well-being $\left(R=.747, R^{2}=.553\right.$, $F=122.403$ ). Interpersonal problem solving explains $55.3 \%$ of the variance in subjective well-being, and it predicts subjective well-being at a significant level. And approaching problems in a negative way $(\beta=-.465 p<.01)$, constructive problem solving $(\beta=.183, p<.01)$, lack of self-confidence $(\beta=-.184, p<.01)$, unwillingness to take responsibility $(\beta=105$, $p<.01)$, and insistent-persevering approach $(\beta=.286 p<.01)$ each subscales of interpersonal problem solving skills important predictors of subjective well-being. And effective interpersonal problem solving skills, such as constructive problem solving and insistent-persevering problem solving skills increased, subjective well-being increased as well. On the other hand, approaching problems in a negative way and lack of self-confidence increased, subjective well-being decreased.

TABLE I: THE Predictive POWER OF INTERPERSONAL Problem SOLVING IN SUBJECTIVE WeLL-BEING

\begin{tabular}{|c|c|c|c|c|c|c|}
\hline Model & & $R$ & $R^{2}$ & $F$ & $\beta$ & $t$ \\
\hline \multirow{5}{*}{$\mathbf{A}$} & $\begin{array}{l}\text { Approaching problems in a negative } \\
\text { way }\end{array}$ & & & & -.465 & 11.39 \\
\hline & Constructive problem solving & & & & .183 & 4.44 \\
\hline & Lack of self-confidence & .747 & .553 & 122.403 & -.184 & 4.63 \\
\hline & Unwillingness to take responsibility & & & & .105 & 2.88 \\
\hline & insistent-persevering approach & & & & .286 & 7.07 \\
\hline
\end{tabular}

A Predictor: Interpersonal problem solving

Dependent variable: Subjective well-being

When Table II is examined, it is seen that there is a significant correlation between loneliness and subjective well-being $\left(R=.670, \quad R^{2}=.448, \quad F=389.370\right)$. Loneliness explains $44.8 \%$ of the variance in subjective well-being, and it predicts subjective well-being at a significant level $(\beta=$ -.670). It is found that when loneliness decreased, subjective well-being increased.

TABLE II: THE PREDICTIVE POWER OF LONELINESS IN SUBJECTIVE WELL-BEING

\begin{tabular}{ccccccc}
\hline \hline Model & $\beta$ & $t$ & $R$ & $R^{2}$ & $\begin{array}{c}\text { Standard } \\
\text { Error }\end{array}$ & $F$ \\
\hline $\mathrm{A}$ & -.670 & 19.95 & .670 & .448 & .089 & 389.370 \\
\hline A Predictor: Loneliness & & & & \\
Dependent variable: Subjective well-being & & \\
\hline \hline
\end{tabular}

\section{CONCLUSION}

The research results are showing that interpersonal problem solving and loneliness are explaining the subjective well-being in a significant level.

One finding of the research is the less interpersonal problem solving skills, such as constructive problem solving and insistent-persevering problem solving levels the less their subjective well-being levels. And also the less, approaching problems in a negative way and lack of self-confidence levels the higher their subjective-well-being levels.

When literature examined, approaching problems in a negative way, and unwillingness to take responsibility was found to have a high level relation with depression and anxiety [14], [15]. Researchers have found that the interpersonal problem solving has a positive correlation with well-being in terms of constructive problem-solving and insistent-preserving approach when other negative dimensions have a negative correlation with it [14]. It seems the finding of this research is parallel with literature.

One other finding acquired at the end of the research is that loneliness is a factor that predicts the subjective well-being in an important level. That is to say, the less the individuals' loneliness levels the higher their subjective well-being levels and also the higher their loneliness levels the lower their subjective well-being. When the literature is examined, there is a relation between subjective well-being with loneliness, too. According to the research findings, the average life satisfaction point of university students with lower loneliness levels is significantly much than those who have higher loneliness levels [30]. Also it is remarking that another predictor of subjective well-being in literature is extroversion [24], [25].

Chalise in his study about the social support, has tried to analyse the changes of mature women and men in their social support levels and to describe what were the main support sources of those individuals loneliness and subjective well-being levels [31]. As a result of the data analysis acquired through face to face interviews a significant relation has been found between loneliness and subjective well-being in a negative manner. In the longitunal researches on non-Hispanic White, African-American and nonblack Latino-American individuals born between 1935-1952 carried out by VanderWeele, Hawkley and Cacioppo between the years 2002-2006, they have examined the correlative effect among the subjective well-being and loneliness. The acquired findings show that loneliness is a meaningful and strong predictor of subjective well-being in that longitunal period [32]. Similarly too many researches are present at that field which found the negative relation between loneliness and subjective well-being or showing that loneliness is a meaningful predictor of subjective well-being [33]-[40]. Loneliness is generally an undesired situation and when experienced excluding the desire of the individual it is accompanied by diverse psychological difficulties. It is expressed as a common idea among the researchers studying on this field, that there is a strong correlation between the feeling of loneliness and psychological/physical well-being [41]. Thus the finding of this research is an expected result.

Consequently it seems the higher problem solving ability and the lower loneliness makes the person happier. During the psychological assistance process, the development of strategies which would increase the interpersonal problem solving capacities and by examining the factors causing loneliness of individuals with high levels of solitude, the arrangement of psycho-education studies oriented on them concerning the communication capabilities and social capabilities, are thought to contribute the individuals' subjective well-being development. 


\section{REFERENCES}

[1] M. T. Dost, "Developing a subjectivewell-being scale: Validity and reliability studies," Turkish Psychological Counseling and Guidance Journal, vol. 3, no. 23, pp. 103-109, 2005.

[2] S. Çam and S. Tümkaya, "The development of interpersonal problem-solving inventory (IPSI): Validity and reliability studies," Turkish Psychological Counseling and Guidance Journnal, vol. 28, issue 3, pp. 95-111, 2007.

[3] A. Demir, "Some factors that affect the loneliness levels of university students," Ph.D. dissertation, dep. Institute of Social Sciences, Hacettepe University, Ankara, 1990.

[4] M. Seligman, Authentic Happiness, New York: Free Press, 2010.

[5] C. R. Snyder and S. J. Lopez, Handbook of Positive Psychology, New York: Oxford University Press, 2002.

[6] R. E. Lucas and E. Diener, Encyclopedia of Applied Psychology, (ed. in chief Charles Spielberger,) Elsevier Academic Press, vol. 3, pp. 669-676, 2004

[7] E. Diener, "Subjective well-being," American Psychologist, vol. 55, issue 1, pp. 34-43, 2000.

[8] E. Diener, "Subjective well-being," Psychological Bulletin, vol. 95, issue 3, pp. 542-575. 1984.

[9] E. Diener and E. Suh, "Measuring quality of life: Economic, social, and subjective indicators," Social Indicator Research,vol. 40, issue 1-2, pp. 189-216, 1997.

[10] E. Diener, E. Suh, and S. Oishi, "Recent finding on subjective well-being," Indian Journal of Clinical Psychology, vol. 24, issue 1, pp 25-41, 1997.

[11] E. Diener, E. Sandvik, and W. Pavot, "Happiness is the frequency, not the intensity, of positive versus negative affect," in Subjective Well-Being an Interdisciplinary Perspective, F. Strack, M. Argyle, and N. Schwarz, Ed., Oxford, England: Pergamon Press, 1991, pp. 119-139.

[12] E. Diener, E. M. Suh, R. E. Lucas, and H. L. Smith, "Subjective well-being: Three decades of progress," Psychological Bulletin, vol. 125, issue 2, pp. 276-302, 1999.

[13] E. Diener, S. O1shı, and E. Lucas, "Personality, culture and subjective well-being: Emotional and cognitive evaluations of life," Annual Review of Psychology, vol. 54, pp. 403-425, 2003

[14] J. A. Feeney and P. Noller, Adult Attachment, Newcastle, UK: Sage 1996.

[15] T. J. D'Zurilla, A. Nezu et al., "What is social problemsolving?: Meanings, models, and measures," in Social Problem Solving: Theory, Research, and Training, in E. C. Chang, T. J. D'Zurilla, and L. J. Sanna, Ed., Washington D.C.: American Psychological Association, 2004, pp. 11-27.

[16] D. S. Pellegrini and E. S. Urbain, "An evaluation of interpersonal cognitive problem solving training with children," Child Psychology and Psychiatry, vol. 26, issue 1, pp. 17-41, 1986.

[17] E. C. Chang, J. Thomas, T. J. D'Zurilla, and L. J. Sanna, "Social problem solving as a mediator of the link between stress andp well-being in middle-adulthood," Cognitive Therapy and Research, vol. 33, issue 1, pp. 33-49, 2009.

[18] A. M. H. Siu and D. T. L. Shek, "Social problem solving as a predictor of well-being in adolescents and young adults," Social Indicators Research, vol. 95, pp. 393-406, 2010.

[19] L. A. Peplau and D. Perlman, "Perspectives on loneliness," in Loneliness: A Sourcebook of Current Theory, Research and Therapy, L A. Peplau and D. Perlman, Ed., New York: Wiley, 1982, pp. 21-39.

[20] R. S. Weiss, Loneliness: The Experience of Emotion and Social Isolation, Cambridge, MA: MIT Press, 1973.

[21] A.Coskuner, "The effects of communication skills development training to the employees' tendency to communication conflicts, loneliness levels and job satisfaction," Ph.D. dissertation, dep. Institute of Social Science, Ankara Üniversitesi, Ankara, 1994.

[22] A. Ç. Özkürkçügil, "Loneliness in prison and its relationship with depression," Crisis Journal, vol. 6, pp. 21-32, 1998.

[23] M. Buluş, "Loneliness among university students," PAÜ Faculty of Education Journal, vol. 3, pp. 82-90, 1997.

[24] R. Larson, "The solitary side of life: An examination of the time people spend alone from childhood to old age," Developmental Review, vol. 10 , pp. $155-183,1990$.

[25] H. W. Jones and L. Hebb, "The experience of loneliness: objective and subjective factors," The International Scope Review, vol. 5, issue 9, pp. 48-69, 2003.

[26] Y. Iwatsubo, F. Derriennic, B. Cassou, and J. Poitrenaud, "Predictors of life satisfaction amongst retired people in Pari," Int J Epidemiol, vol. 25, pp. 160-170, 1996.

[27] P. T. Costa and R. R. McCrae, "Influence of extroversion and nevroticism on subjective well-being: Happy and unhappy people,"
Journal of Personality and Social Psychology, vol. 38, pp. 668-678, 1980.

[28] D. Watson and L. A. Clark, "On traits and temperament: General and specific factors of emotional experience and their relation to the five-factor model," Journal of Personality, vol. 60, issue 2, pp 441-476, 1992

[29] D. Russell, L. A. Peplau, and M. L. Ferguson, "Developing a measure of loneliness," Journal of Personality Assessment, vol. 42, pp. 290-294, 1978.

[30] D. Russell, L. A. Peplau, and C. E. Cutrona, "The revised UCLA Loneliness Scale: Concurrent and discriminate validity evidence," Journal of Personality and Social Psychology, vol. 39, pp. 472-480, 1980.

[31] H. N. Chalise, "Social support and its correlation with loneliness and subjective well-being: A cross-cultural study of older Nepalese adults," Asian Social Work and Policy Review, vol. 4, pp. 1-25, 2010.

[32] T. J. V. Weele, L. C. Hawkley, and J. T. Cacioppo, "On the reciprocal association between loneliness and subjective well-being," American Journal of Epidemiology, vol. 176, issue 9, pp. 777-784, 2012.

[33] K. S. Mellor and R. J. Edelman, "Mobility, social support, loneliness and well-being amongst two groups of older adults," Personal Individual Differences, vol. 1, pp. 1-5, 1988.

[34] C. L. Cohen, N. Talavera, and R. Hartung, "Depression among aging persons with schizophrenia who live in the community," American Journal of Geriatric Psychiatry, vol. 5, issue 2, pp. 145-55, 1997.

[35] L. Borge, E. W.Martinsen, T. Rudd, Ø. Watne, and S. Fris, "Quality of life, loneliness, and social contact among long-term psychiatric patients," Psychiatric Services, vol. 50, issue 1, pp. 81-4, January 1999

[36] N. Steverink, G. J. Westerhof et al., "The personal experience of aging, individual resources and subjective well-being," Journal of Gerontology: Psychological Sciences, vol. 56, pp. 364-73, 2001.

[37] F. Bozorgpour and A. Salimi, "State self-esteem, loneliness and life satisfaction," Social and Behavioral Sciences, vol. 68, pp. 2004-2008 2012.

[38] M. N. Akhunlar, "An investigation about the relationship between life satisfaction and loneliness of nursing students in uşak university," Procedia-Social and Behavioral Science, vol. 5, pp. 2409-2415, 2010.

[39] A. Salimi, "Social-emotional loneliness and life-satisfaction," Social and Behavioral Science, vol. 29, pp. 292-295, 2011.

[40] C. Vara, P. Chedraui et al., "Life satisfaction, loneliness and related factors during female midlife," Maturitas, vol. 72, pp. 88-92, 2012.

[41] P. M. Murphy and G. A. Kupshik, Loneliness, Stress, and Well-Being: A Helper's Guide, New York: Routledge, 1992.

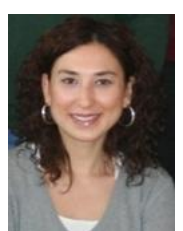

Yeliz Saygın was born in Beyşehir in 1985. She received her undergraduate education at Selcuk University, Psychological Counselling and Guidance Department, in 2006 and also earned master degree from the same Department in 2008. She is currently pursuing a doctora degree at University of Necmettin Erbakan. Her researches focused on positive psychology. She subsequently served as a faculty member at Necmettin Erbakan University as a research assistant. Ms. Saygin is a founding member of Turkish Psychological Counseling and Guidance Association.

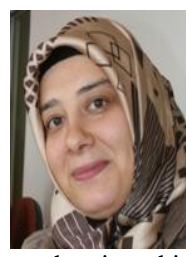

Seher Akdeniz was born in Ankara in 1981. She received her undergraduate education at Selcuk University, Psychological Counselling and Guidance department, in 2006 and also earned master degree from the same department in 2009. She is currently pursuing a doctoral degree at University of Necmettin Erbakan. She is interested in issues related to positive psychology, compassion and well-being. She is working as a guidance teacher in a high school in Konya. Ms.Akdeniz is a member of Turkish Psychological Counseling and Guidance Association.

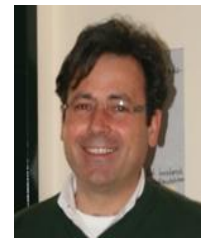

M. Engin Deniz was born in 1971 in İskilip. He received his master's degree and $\mathrm{PhD}$ in Counseling and Guidance from Selcuk University at Konya, Türkiye. He has authored or coauthored 14 books, approximately 50 journal article publications and delivered over 40 presentations in international and national conferences seminars, in some of them as invited speaker. He has undertaken teaching and research work in the field of developmental guidance, social skills, child psychology etc. Prof. Deniz was the founding member of Turkish Psychological Counseling and Guidance Association, for six years. He is currently serving as the dean of Faculties of Education and Technical Education at Düzce Universityand a professor of the Counseling Program at YıldızTeknik University, İstanbul. 